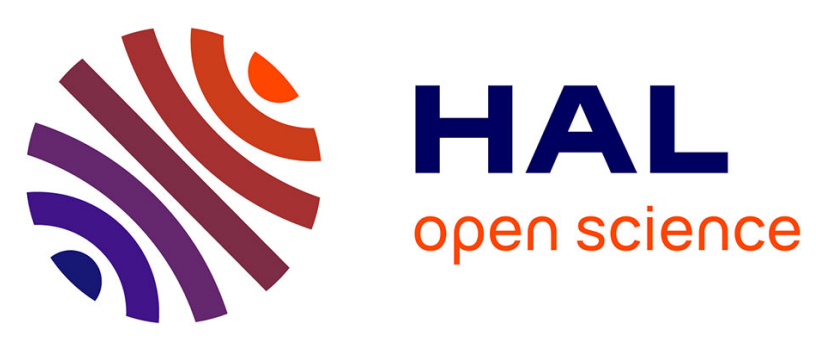

\title{
Validation of Melampsora larici-populina reference genes for in planta RT-quantitative PCR expression profiling during time-course infection of poplar leaves
}

Stéphane S. Hacquard, Claire Veneault-Fourrey, Christine Delaruelle, Pascal Frey, Francis Martin, Sébastien Duplessis

\section{To cite this version:}

Stéphane S. Hacquard, Claire Veneault-Fourrey, Christine Delaruelle, Pascal Frey, Francis Martin, et al.. Validation of Melampsora larici-populina reference genes for in planta RT-quantitative PCR expression profiling during time-course infection of poplar leaves. Physiological and Molecular Plant Pathology, 2011, 75 (3), pp.106-112. 10.1016/j.pmpp.2010.10.003 . hal-02644005

\section{HAL Id: hal-02644005 \\ https://hal.inrae.fr/hal-02644005}

Submitted on 28 May 2020

HAL is a multi-disciplinary open access archive for the deposit and dissemination of scientific research documents, whether they are published or not. The documents may come from teaching and research institutions in France or abroad, or from public or private research centers.
L'archive ouverte pluridisciplinaire HAL, est destinée au dépôt et à la diffusion de documents scientifiques de niveau recherche, publiés ou non, émanant des établissements d'enseignement et de recherche français ou étrangers, des laboratoires publics ou privés. 


\title{
Validation of Melampsora larici-populina reference genes for in planta RT-quantitative PCR expression profiling during time-course infection of poplar leaves
}

\author{
Stéphane Hacquard, Claire Veneault-Fourrey, Christine Delaruelle, Pascal Frey, \\ Francis Martin, Sébastien Duplessis* \\ INRA (Institut National de la Recherche Agronomique), Unité Mixte de Recherche 1136 INRA/Nancy Université 'Interactions Arbres/Micro-organismes', \\ Centre INRA de Nancy, 54280 Champenoux, France
}

\section{A R T I C L E I N F O}

\section{Article history:}

Accepted 29 October 2010

\section{Keywords:}

Populus

Poplar rust

Biotrophic fungus

Gene expression

Housekeeping genes

Thiamine

\begin{abstract}
A B S T R A C T
The foliar rust caused by Melampsora larici-populina ( $\mathrm{Mlp})$ is the main disease affecting poplar plantations in Europe. The biotrophic status of this fungus is a major limitation to address in planta transcripts profiling. Thus, identification of reference rust genes steadily expressed during plant tissue colonization is a crucial point. A quantitative PCR approach to assess fungal ITS amplification profile and Reverse Transcription quantitative-PCR was set to compare candidate reference genes amplification profiles in poplar infected tissues. We selected two M. larici-populina genes encoding an alpha-tubulin and the elongation factor-1-alpha that showed the highest expression stability across biological samples and for which transcript levels were correlated with fungal ITS amplification during time-course infection of poplar leaves. We report the use of these reference genes to assess in planta expression profiles of two genes involved in thiamine biosynthesis (THI1 and THI2) for which specific haustorium expression was previously described in the bean rust fungus Uromyces fabae. Mlp-THI1 and Mlp-THI2 showed similar expression profiles. Trancripts were barely detectable in urediniospores as well as during the early stages of infection compared to those reported in the bean rust, whereas a strong induction was observed after haustorial formation after $24 \mathrm{hpi}$. These data are in frame with the results obtained in $U$. fabae and consistent with a metabolic reorientation that likely occurs after the fungus derived nutrients from its host in the haustorial structure essential for fungal biotrophy.
\end{abstract}

(C) 2010 Elsevier Ltd. All rights reserved.

\section{Introduction}

Rust caused by Melampsora larici-populina is the main disease affecting poplar plantations in Europe with severe economic losses [1]. Epidemiology of the disease and poplar defence responses have been previously addressed [2,3] but still very little is known about fungal molecular mechanisms during the infection process. It is crucial to increase our understanding of the biology of the pathogen in order to develop strategies to control the disease. In the wake of the Populus genome sequencing [4], the $\sim 100 \mathrm{Mb}$ genome of $M$. larici-populina has been recently sequenced by the Joint

Abbreviations: $\mathrm{Cq}$, quantification cycle; EST, expressed sequence tag; ITS internal transcribed spacer; LPI, leaf plastochrony index; Mlp, Melampsora laricipopulina; qPCR, quantitative polymerase chain reaction; rDNA, ribosomal DNA; RT, Reverse Transcription.

* Corresponding author. Tel.: +33 3833940 13; fax: +33 383394069 .

E-mail address: duplessi@nancy.inra.fr (S. Duplessis).
Genome Institute (JGI; http://genome.jgi-psf.org/Mellp1/Mellp1. home.html) and the analysis of this genome is a great opportunity to identify effector genes expressed by the rust fungus to achieve plant infection [3,5]. Availability of the genome sequences of both the plant host and the rust fungus and recent updates on Populus defence reactions upon rust infection [6,7,8], make the Populus/Melampsora pathosystem an emerging model in forest pathology to study the molecular mechanisms developed by rust to infect plant tissues and to feed on the host [3].

The biotrophic status of rust fungi precludes some routine manipulations in the laboratory. Up to now, most of the knowledge gained on rust gene expression was obtained after sequencing of Expressed Sequence Tags (EST) from urediniospores, haustorial tissues or infected plant tissues [5,9,10,11]. A synthetic system has been established to study the development of Uromyces fabae infection structure after the growth of urediniospores on polyethylene membranes [12]. By this means, it is possible to follow transcripts accumulation in most fungal structures usually formed 
in planta after penetration in the leaf tissue, i.e. germtubes, appressoria, primary infection hyphae and haustorial mother cells. Beside, semi-quantitative PCR was used to monitor in planta gene expression of $U$. fabae during bean infection [13,14]. Another method developed to specifically isolate haustoria from infected bean leaves also allowed measuring transcript levels in this structure $[9,11,15]$. Such approaches led to the description of specific haustorial expression profiles for several rust genes such as the thiamine biosynthesis genes THI1; THI2, the hexose transporter HXT1 and the Rust Transferred Protein RTP1 [15,16,17].

Great progresses have been made in epidemiology after the development of the quantitative-PCR (qPCR) technique that allows a better detection of fungal pathogens in planta $[18,19,20,21]$. Such technique was successfully applied to the poplar leaf rust disease and has allowed to assess M. larici-populina progression in the plant tissue through specific amplification of fungal internal transcribed spacer (ITS) by qPCR $[7,19]$. Due to its sensitivity and ease of use in routine in laboratory, qPCR is now a technique of choice to study gene expression, although it requires rigorous standardization to accurately interpret the data and generate reliable results [22]. Based on the specificity of primers to target fungal sequence and to its great sensitivity, qPCR is a perfect tool to follow-up accumulation of specific fungal transcripts in planta. However, in order to allow comparison of expression levels in time-course experiments to draw-up expression profiles, reference genes are required to take into account differences in fungal content between different timepoints $[23,24]$.

Here we present an expression assay of five reference fungal genes commonly used in molecular studies, by Reverse Transcription (RT) semi-quantitative-PCR (semi-qPCR) and qPCR during time-course infection of leaves from resistant and susceptible poplar cultivars challenged by M. larici-populina strain 98AG31. Based on their expression levels and stability and comparison to fungal ITS amplification profiles in planta, we selected alphatubulin (Mlp-aTUB) and elongation factor-1-alpha (Mlp-ELF1a) as candidate reference genes for $M$. larici-populina gene expression in planta. Finally, we report the use of these reference genes to derive expression profiles of genes for which specific haustorium expression was previously described in the bean rust fungus $U$. fabae during a compatible poplar-rust interaction.

\section{Material and methods}

\subsection{Plant material, growth conditions and inoculation procedures}

All experiments were performed on rooted cuttings of Populus trichocarpa x Populus deltoides 'Beaupré' (susceptible cultivar) and 'Hoogvorst' (resistant cultivar). For the analysis of incompatible and compatible poplar-rust interactions, plants were grown in greenhouse from dormant cuttings as previously described [7]. Isolate 98AG31 of M. larici-populina (pathotype 3-4-7, virulent on 'Beaupré', avirulent on 'Hoogvorst'), was used in this study and was grown on detached leaves of susceptible P. deltoides $\times$ Populus nigra 'Robusta' as previously reported [7]. Expanded leaves from leaf plastochrony index (LPI) 5 to 9 were detached from several 'Beaupré' and 'Hoogvorst' plants and were spray-inoculated on their abaxial surface with an urediniospore suspension (100,000 urediniospores/ $\mathrm{ml}$ ) or with water-agar as a control (mock-inoculated leaves) as described in Rinaldi et al. [7]. Inoculations were done by pooling leaves of different LPI from different plants for each treatment (i.e. compatible, incompatible and mock-inoculation) and each time point. The inoculated leaves were incubated with the abaxial surface uppermost, floating on deionized water in Petri dishes, at $19 \pm 1{ }^{\circ} \mathrm{C}$ under continuous artificial illumination, for various durations. The material harvested at different time points in the different treatments consisted of $30 \mathrm{~mm}$ diameter leaf discs randomly sampled on the overall leaf surface. The leaf discs were immediately snap-frozen in liquid nitrogen and transferred to $-80^{\circ} \mathrm{C}$.

\subsection{DNA and RNA extraction}

Total DNA was extracted from leaf tissues with the DNeasy Plant Mini kit (Qiagen, Courtaboeuf, France) from $100 \mathrm{mg}$ of frozen $\left(-80^{\circ} \mathrm{C}\right)$ material. RNA was removed by the addition of ribonuclease A during extraction. DNA quality was verified by electrophoresis on agarose gel, and DNA quantity was measured by spectrophotometry [25].

Isolation of total RNA was performed with the RNeasy Plant Mini kit (Qiagen) from $100 \mathrm{mg}$ of pooled $\left(-80^{\circ} \mathrm{C}\right)$ foliar disks harvested from leaves of various LPI and various individual poplar plants for each treatment considered. Pooling of samples from different trees and LPI helped in minimizing the variations between individual RNA samples. A DNase I (Qiagen) treatment was included in the RNA isolation procedure according to the manufacturer's instructions to eliminate traces of genomic DNA. Quality and quantity of RNA samples were checked with the RNA analyzer Experion (BioRad, Marnes la Coquette, France) following the manufacturer's recommendation.

\subsection{ITS amplification by semi-quantitative and quantitative-PCR}

In planta development of the rust fungus was followed in 'Beaupré' and 'Hoogvorst' by specific amplification of the nuclear ribosomal DNA (rDNA) ITS on total DNA isolated from inoculated leaf tissues [7,19]. Amounts of $100 \mathrm{ng}$ and $10 \mathrm{ng}$ DNA were used respectively for semi-qPCR and qPCR amplifications with ITS primers specific for poplar and for M. larici-populina (Table 1). Specificity of ITS primers was validated in silico with $M$. laricipopulina ITS sequences available at the JGI M. larici-populina genome portal (http://genome.jgi-psf.org/Mellp1/Mellp1.home. $\mathrm{html}$ ) and in international databases. In order to improve qPCR amplification efficiency, we designed a new set of M. larici-populina ITS primers amplifying a $169 \mathrm{bp}$ fragment shorter than those previously described in $[7,19]$. These primers also matched other Melampsora spp. in the non-redundant nucleotide database at the National Center for Biotechnology Information (BLASTN), thus, although perfectly suited for molecular studies with controlled M. larici-populina inoculation, these primers should not be used with infected plants collected in field experiments due to the risk of cross-hybridization with other rust species. Semi-qPCR amplification was performed in $25 \mu \mathrm{L}$ reaction volumes using $10 \mu \mathrm{M}$ of primers with following amplification parameters: $95{ }^{\circ} \mathrm{C}$ for $5 \mathrm{~min}$, then $95^{\circ} \mathrm{C}$ for $1 \mathrm{~min}, 60^{\circ} \mathrm{C}$ for $30 \mathrm{~s}, 72^{\circ} \mathrm{C}$ for 1 min for a maximum of 35 cycles. For qPCR, amplifications were performed in $1 \mathrm{X}$ iQ SYBR Green Supermix (Bio-Rad) with $1.6 \mu \mathrm{M}$ of specific $5^{\prime}$ and $3^{\prime}$ ITS primers with an MJ-opticon2 DNA engine (Bio-Rad). Assuming a signal intensity proportional to amplified ITS sequences, we considered the pathogen growth as the relative difference between cycle threshold or quantification cycle (Cq) of fungal ITS amplicons quantified in the compatible interaction compared to Cq of poplar ITS amplicons at 2, 6, 12, 24, 48, 96 and 168 h postinoculation (hpi) $\left(2^{-\Delta \mathrm{Cq}}\right.$ calculation, [26]). PCR amplifications were carried out on two biological replicates and included two distinct technical replicates.

\subsection{Transcript profiling through semi-quantitative and quantitative RT-PCR}

To allow the amplification of specific transcripts by RT followed by either semi-qPCR and qPCR, we designed primers for the following $M$. larici-populina genes retrieved from the M. larici- 
Table 1

Specific 5' and $3^{\prime}$ primers designed for qPCR and semi-qPCR amplification of Melampsora larici-populina and Populus ITS and amplification of Melampsora larici-populina transcripts during controlled poplar-rust time-course infection. Primers of Laccaria bicolor MISSP8 gene used to test amplification inhibition are also detailed.

\begin{tabular}{|c|c|c|c|c|c|}
\hline Accession no. & Target sequence & $5^{\prime}$ primer & $3^{\prime}$ primer & $\begin{array}{l}\text { Amplicon } \\
\text { length }\end{array}$ & $\begin{array}{l}\text { Primer } \\
\text { Efficiency (\%) }\end{array}$ \\
\hline \multicolumn{6}{|l|}{$\mathrm{NCBI}^{\mathrm{a}}$} \\
\hline AJ006438 & Populus ITS & GAAGCGCCAAGGAAATTGA & GCGTTCAAAGACTCGATGGT & 192 & 84 \\
\hline AY375268 & Melampsora ITS & TCGGCCCTCATTCTTTCTAA & GATAGTCGGAGCGACCAAAG & 169 & 107 \\
\hline \multicolumn{6}{|l|}{ JGI proteinID ${ }^{\mathrm{b}}$} \\
\hline 45600 & Actin (ACT) & GGCACCTCTTAATCCAAAAGTC & GTGAGTAACACCGTCACCAGAA & 163 & 91 \\
\hline 73137 & Alpha-tubulin (aTUB) & CAAGCGTACCATTCAGTTCGT & САСССТССТССАТАССТТСТС & 239 & 94 \\
\hline 73378 & Elongation factor-1-alpha (ELF1a) & CGAGACTCCCAAATACTTCGTT & GTTCACGAGTTTGACCATCCTT & 167 & 102 \\
\hline 46086 & $\begin{array}{l}\text { Glyceraldehyde-3-phosphate- } \\
\text { dehydrogenase (GAPDH) }\end{array}$ & CCATCAACGACCCCTTTATC & ATCGGCACCAGATTTACCC & 185 & 92 \\
\hline 40152 & Histone H4 (HISTH4) & GAGGAAAATCCGGTGGAAAG & TGGCATGTTCGGTGTAGGTA & 225 & 99 \\
\hline 67013 & Thiamine biosynthesis gene 1 (THI1) & GCTTCTGCTCCATCCTTTACAT & GATTTGGTTAAGTGGGCTGTTC & 179 & 97 \\
\hline 53832 & Thiamine biosynthesis gene 2 (THI2) & CTCTCGTATCGAAGGCAACTCT & CTCCTCCATGTCGTTGAAGTATC & 161 & 95 \\
\hline $388224^{c}$ & $\begin{array}{l}\text { Mycorrhiza-induced small } \\
\text { secreted protein MISSP8 }\end{array}$ & AGCTGATCTCAACGGAGACGTTGAGGCC & TCAATCACTATCGCGCCTCCAGTCAC & 118 & 121 \\
\hline
\end{tabular}

populina JGI genome portal (Table 1 ): actin, alpha-tubulin, elongation factor-1-alpha, glyceraldehyde-3-phosphate-dehydrogenase, histone H4, thiamine 1 THI1 (U. fabae THI1 homologue previously described as PIG1; [9]) and thiamine 2 THI2 (U. fabae THI2 homologue previously described as PIG4 [9]). The primers were designed in the coding sequence, and amplified fragments showed expected lengths ranging between 161 and 239 nucleotides (Table 1). Primers efficiency was assessed for each target sequence and ranged between 91 and 102\%. A BLASTN search was performed against the $P$. trichocarpa genome sequence [4] with each primer sequence to verify the absence of cross annealing in the poplar genome sequence. First-strand cDNAs were synthesized by RT from $1 \mu \mathrm{g}$ DNase-treated total RNA using the iScript cDNA synthesis kit (Bio-Rad) in a total volume of $20 \mu \mathrm{L}$ according to the manufacturer's instructions. For the semi-qPCR amplification, $1 \mu \mathrm{L}$ of cDNA was amplified by PCR $\left(95^{\circ} \mathrm{C}\right.$ for $5 \mathrm{~min}$, then $95^{\circ} \mathrm{C}$ for $1 \mathrm{~min}$, $60{ }^{\circ} \mathrm{C}$ for $30 \mathrm{~s}, 72^{\circ} \mathrm{C}$ for $1 \mathrm{a}$ min for a maximum of 35 cycles) in $25 \mu \mathrm{L}$ reaction volume using $10 \mu \mathrm{M}$ of primers. For the qPCR amplification, $2 \mu \mathrm{L}$ of one-tenth diluted RT products were amplified in $1 \mathrm{X}$ iQ SYBR Green Supermix (Bio-Rad) with $1.6 \mu \mathrm{M}$ of specific 5'- and 3'primers with an MJ-opticon2 DNA engine (Bio-Rad). M. larici-populina gene expression was normalized to reference genes, a-tubulin (Mlp-aTUB) and elongation factor-1-alpha (Mlp-ELF1a) using the $2^{-\Delta \mathrm{Cq}}$ calculation [26], and expressed relative to the highest expression level, set at $100 \%$. The GeNorm VBA Applet for Microsoft Excel (http://medgen.ugent.be/ jvdesomp/genorm/) based on the principles and calculations described in Vandesompele et al. [27] helps to identify most stably expressed reference genes in a given panel of samples for qPCR normalization. This approach was used to compare the selected $M$. larici-populina candidate reference genes to select stably expressed housekeeping genes. In order to validate the absence of amplification inhibition in any of the rust infected plant samples tested in this study, we used the Laccaria bicolor gene encoding MISSP8, a protein specific of L. bicolor (http:// genome.jgi-psf.org/Lacbi1/Lacbi1.home.html, protein ID 388224), as a spike control [28]. This gene was cloned in the plasmid TOPOPCR2 (Invitrogen, Cergy-Pontoise, France) and primers were designed to specifically amplify a 118 bp region in the target gene (Table 1). Primers did not match any loci of the P. trichocarpa or the M. larici-populina genomes. An aliquot of $0.1 \mathrm{ng}$ of the pLbiMISSP8 plasmid was added to each biological sample of the time-course serie (three biological replicates) and amplification of LbiMISSP8 was performed by qPCR as decribed above. LbiMISSP8 Cq in poplar- rust samples were then compared to Cq obtained from a $0.1 \mathrm{ng}$ control plasmid sample.

\section{Results}

3.1. M. larici-populina growth in poplar leaves during compatible and incompatible interactions

In planta growth of $M$. larici-populina strain 98AG31 was limited during the early stages of 'Beaupré' leaves infection (2, 6 and $12 \mathrm{hpi}$; Fig. 1). A slow increase of fungal ITS amount was observed between 12 and 48 hpi (6-fold) while a drastic increase of about 70-fold was measured between 48 and $96 \mathrm{hpi}$, indicating a fast colonization of the plant mesophyll by the rust fungus during the compatible interaction. A fungal growth slackening was observed between 96 and $168 \mathrm{hpi}$, the later time-point corresponding to urediniospores formation. Interestingly, at the end of the time-course infection, fungal ITS amount in 'Beaupré' leaves was about 7000-fold higher than the amount measured at the earliest time-point ( $2 \mathrm{hpi})$. At the contrary, M. larici-populina strain 98AG31 growth was limited during the whole time-course infection of 'Hoogvorst' leaves, corresponding to an incompatible poplar-rust interaction (Fig. 1). These fungal growth profiles confirm and extend the results

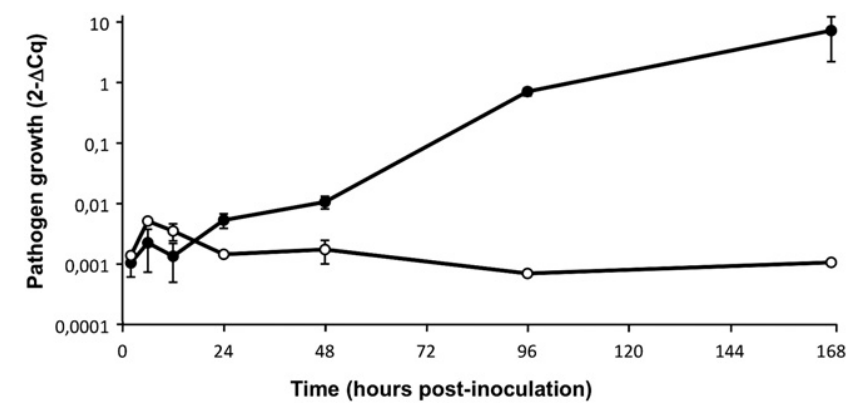

Fig. 1. Time-course infection of poplar 'Beaupré' (susceptible cultivar, black dots) and 'Hoogvorst' (resistant cultivar, white dots) leaves by M. larici-populina strain 98AG31. Development of the rust strain was monitored by specific quantitative PCR amplification of the rDNA intergenic ITS region from total DNA extracted from inoculated leaf tissues at 2, 6, 12, 24, 48, 96, 168 h post-inoculation. Pathogen growth curves correspond to fungal ITS amplicons compared to poplar ITS amplicons $\left(2^{-\Delta \mathrm{Cq}}\right)$. Note the $\log$ scale. 
described by Rinaldi et al. [7] during the poplar-rust interaction. Whereas Rinaldi et al. [7] compared compatible and incompatible poplar-rust interactions based on the growth curves of two distinct M. larici-populina strains (i.e. virulent and avirulent) on the same poplar cultivar ('Beaupré'), the results presented here corresponded to the same M. larici-populina strain infecting two poplar cultivars with distinct genetic resistance background. Interestingly, similar fungal growth profiles were observed independently of the combination of cultivars/strains between 2 and 96 hpi. In the present study, the time-course was extended to the uredinia formation and urediniospores production, indicating that the uredinial stage is marked by a drastic increase in fungal mass in planta.

\section{2. $R T$-semi-qPCR expression profiles of M. larici-populina reference genes}

In order to accurately measure the relative abundance of a target transcript, normalization to stable reference transcripts is required $[26,27,28,29]$. Expression level of the typical fungal reference genes actin (Mlp-ACT), glyceraldehyde-3-phosphate-deshydrogenase (Mlp-GAPDH), alpha-tubulin (Mlp-aTUB), elongation factor-1-alpha (Mlp-ELF1a) and histone H4 (Mlp-HISTH4) in M. larici-populina was assessed by semi-qPCR during incompatible and compatible

A

Time (hours post-inoculation)

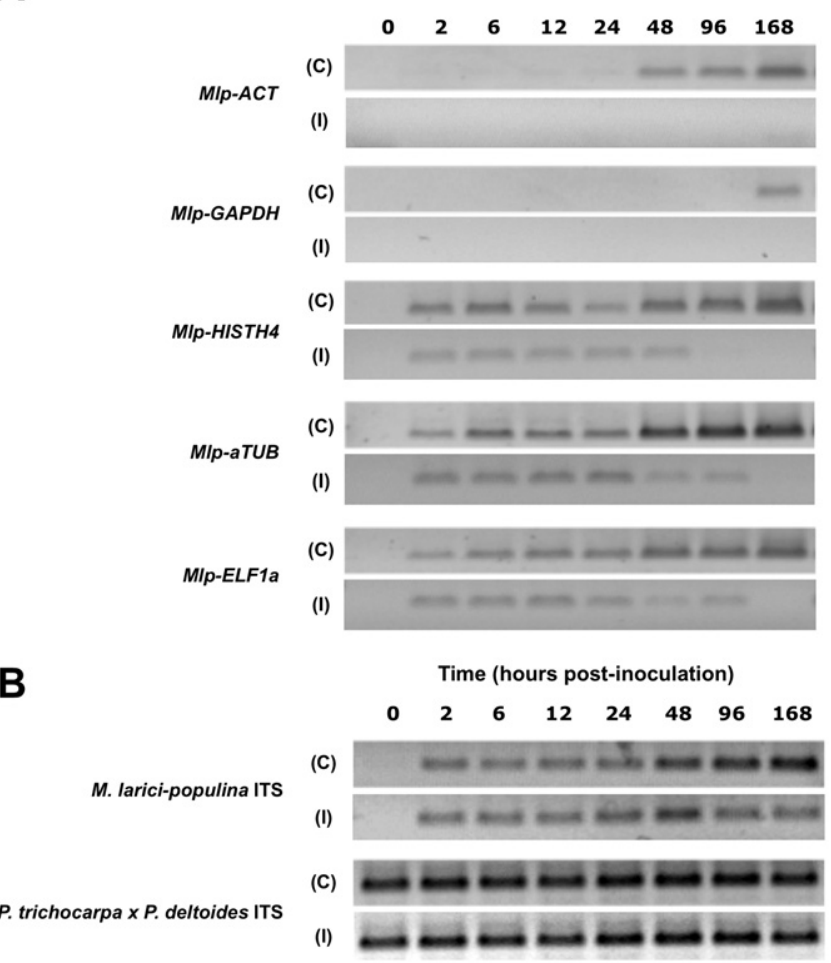

Fig. 2. Semi-quantitative RT-PCR expression profiles for M. larici-populina transcripts encoding actin (Mlp-ACT), alpha-tubulin (Mlp-aTUB), elongation factor-1-alpha (MlpELF1a), glyceraldehyde-3-phosphate-deshydrogenase (Mlp-GAPDH), histone H4 (MlpHISTH4) during time-course infection of $P$. trichocarpa $\times P$. deltoides 'Beaupré' (compatible interaction, C) and 'Hoogvorst' (incompatible interaction, I) leaves at 2, 6, $12,24,48,96$ and $168 \mathrm{~h}$ post-inoculation (hpi) and non inoculated leaves $(0 \mathrm{~h})$. A, total RNA of 'Beaupré' or 'Hoogvorst' leaves inoculated with M. larici-populina strain 98AG31 was isolated and aliquots of $1 \mu \mathrm{g}$ were used for first-strand cDNA synthesis. PCR was performed using $1 \mu \mathrm{l}$ of first-strand cDNA. A control with no RT in the first-strand cDNA synthesis reaction mix was included to control for the lack of genomic DNA. B, PCR amplification of poplar and fungal ITS fragments from DNA samples are indicated as a reference of in planta fungal growth progression. In Fig. 2A and B, amplified DNA was sampled after a total of 35 cycles of PCR. interactions (Fig. 2A) and compared to fungal ITS semi-qPCR amplification profiles (Fig. 2B). Transcripts of these genes were not detected or detected at lower levels during the incompatible interaction compared to the compatible one, consistent with the lower growth noticed by fungal ITS amplification (Figs. 1 and 2). During the compatible interaction, Mlp-ACT and Mlp-GAPDH were not or barely detectable at early stages of infection and thus might not be proper reference genes in the corresponding biological situations. In contrast, Mlp-aTUB, Mlp-ELF1a and Mlp-HISTH4 were detected at all time-points of the infection process in the compatible interaction. Semi-qPCR profiles of these candidate genes were comparable to M. larici-populina ITS profile (Fig. 2) and might represent candidate reference genes. Accuracy of these $M$. laricipopulina reference genes was further tested by RT-qPCR.

\section{3. $q P C R$ amplification inhibition assay}

The absence of amplification inhibition was verified in our experimental system using the SPUD assay described by Nolan et al. [28] with MISSP8 a specific gene of the symbiotic basidiomycete L. bicolor as a spike control gene. For this, $0.1 \mathrm{ng}$ of plasmid pLbiMISSP8 were added to cDNA and genomic DNA samples corresponding to the time-course infection series used in the study for semi-qPCR and qPCR, then qPCR amplification cycle Cq of the 118 bp MISSP8 cDNA were compared with the sole plasmid. Identical $\mathrm{Cq}$ values were recovered for the different biological situations and the control plasmid validating the absence of amplification inhibition in the poplar-rust interactions samples (Supplemental Fig. 1).

\subsection{Validation of M. larici-populina reference genes expression profiles by $R T-q P C R$}

To validate the use of $M$. larici-populina candidate reference genes as relative controls in expression studies of compatible poplar-rust interaction, we tested their amplification by RT-qPCR and compared the M. larici-populina ITS Cq to reference genes Cq during time-course infection of 'Beaupré' leaves. The low expression of Mlp-GAPDH observed by semi-qPCR was confirmed, indicating that this gene is not suitable for normalization during time-course infection. Remaining candidate reference genes were all detected and $\mathrm{Cq}$ could be determined and compared to fungal ITS Cq (Fig. 3A). Although all tested genes presented similar profiles at late stages of infection, differences were observed between 2 and $24 \mathrm{hpi}$. Indeed, Mlp-HISTH4 and Mlp-ACT both showed a higher Cq at 24 hpi inconsistent with the ITS Cq (Fig. 3A). GeNorm [27] was used to define the qPCR expression stability of the four genes. Mlp$a T u b$ and Mlp-ELF1a showed the lowest expression stability values (M) which correspond to the most stable expressed genes (Fig. 3B). Based on the qPCR profiles and the GeNorm assay, we picked-up the Mlp-aTub and the Mlp-ELF1a as the best candidate reference genes for RT-qPCR normalization. To further validate the use of those two reference genes, a total of five distinct technical replicates of Mlp-aTUB and Mlp-ELF1a RT-qPCR amplification (three biological replicates in each assay) were performed by two different manipulators in different laboratory conditions such as different laboratories, different days, different iQ SYBR Green Supermixes (Bio-Rad) and different pools of cDNA synthesized from the same RNA (technical replicates $1-5$ in Supplemental Fig. 2).

At early stages of infection, Mlp-aTUB and Mlp-ELF1a could be detected with a $\mathrm{Cq}$ of 30 and 29 cycles respectively (Fig. 3A), although the in planta fungal biomass was rather low compared to later time-points. During the infection process, the $\mathrm{Cq}$ of those genes showed similar decreases to 17 and 16 cycles respectively, at 168 hpi. Cq profiles of reference genes and ITS were almost comparable during the overall time-course infection. The curves 


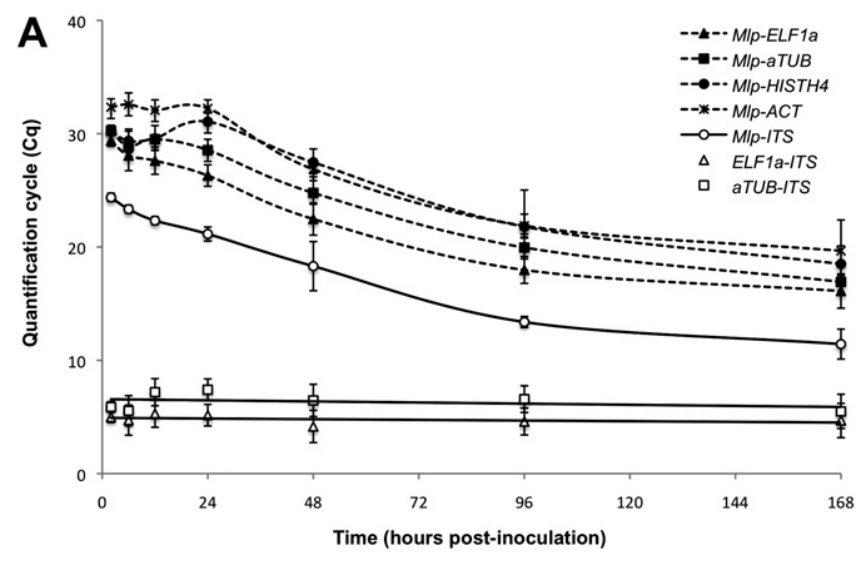

B

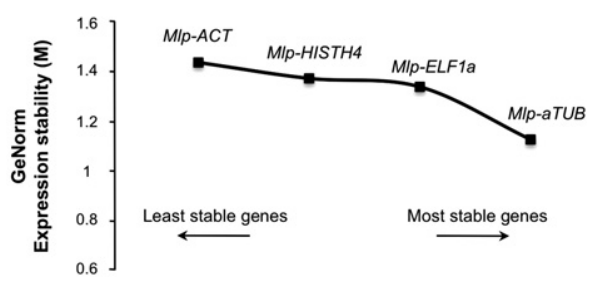

Fig. 3. Comparison of quantitative PCR (qPCR) quantification cycle Cq between fungal ITS fragments and fungal transcripts encoding an actin (Mlp-ACT), an alpha-tubulin (Mlp-aTUB), an elongation factor-1-alpha (Mlp-ELF1a) and an histone H4 (Mlp-HISTH4) amplified from $P$. trichocarpa $\times$ P. deltoides 'Beaupré' infected leaves during time-course infection with $M$. larici-populina strain 98AG31. A, M. larici-populina ITS Cq were measured by qPCR from DNA isolated from inoculated leaves at 2, 6, 12, 24, 48, 96, 168 hpi. Mlp-ACT, Mlp-aTUB, Mlp-ELF1a and Mlp-HISTH4 transcripts Cq were obtained by RT-qPCR from total RNA isolated from the same tissues at the same time-points. Direct subtraction of ITS Cq from Mlp-aTUB and Mlp-ELF1a transcripts Cq shows a linear correlation between $\mathrm{Cq}$, respectively $y=0.004 \times+6.58\left(R^{2}=0.11\right)$ and $y=0.002 \times+4.92\left(R^{2}=0.16\right)$, during time-course infection of poplar leaves. B, Expression stability values (M) of Mlp-ACT, Mlp-aTUB, Mlp-ELF1a and Mlp-HISTH4 candidate reference genes calculated with GeNorm. Lowest $M$ value indicates most stable expressed genes.

obtained with Mlp-aTUB and Mlp-ELF1a genes were parallel to that obtained with ITS, suggesting a strong correlation between reference genes expression and fungal biomass content in plant tissue during time-course infection. Subtraction of the ITS Cq from MlpaTUB and Mlp-ELF1a transcripts Cq shows parallel slopes (Fig. 3A), respectively of $y=0.004 \times+6.58\left(R^{2}=0.11\right)$ and $y=0.002 \times+4.92$ $\left(R^{2}=0.16\right)$, indicating a good correlation between reference genes expression and fungal biomass content in plant tissue during timecourse infection.

\section{5. $R T-q P C R$ expression assays}

RT-qPCR analysis was used to investigate the relative expression of Mlp-THI1 and Mlp-THI2, two homologs of thiamine biosynthesis genes highly expressed in haustoria as previously reported in U. fabae $[9,16]$. cDNA templates derived from M. larici-populina ungerminated urediniospores and infected 'Beaupré' leaves $(2,6$, $12,24,48,96,168 \mathrm{hpi}$ ) were used to follow in planta transcript profiles during compatible poplar-rust interaction. Mlp-aTUB and Mlp-ELF1a were used as constitutively expressed endogenous controls for normalization of gene expression. Mean Cq of the two genes was considered at each time-points for $2^{-\Delta \mathrm{Cq}}$ calculations. Calculations performed separately with either Mlp-aTUB or MlpELF1a as a unique reference gene, did not show significant differences (data not shown). Thus, the mean Cq of the two reference genes was used rather than comparison to a single reference gene. Mlp-THI1 and Mlp-THI2 were both expressed in M. larici-populina during plant infection after 48 hpi and 24 hpi respectively (Fig. 4).
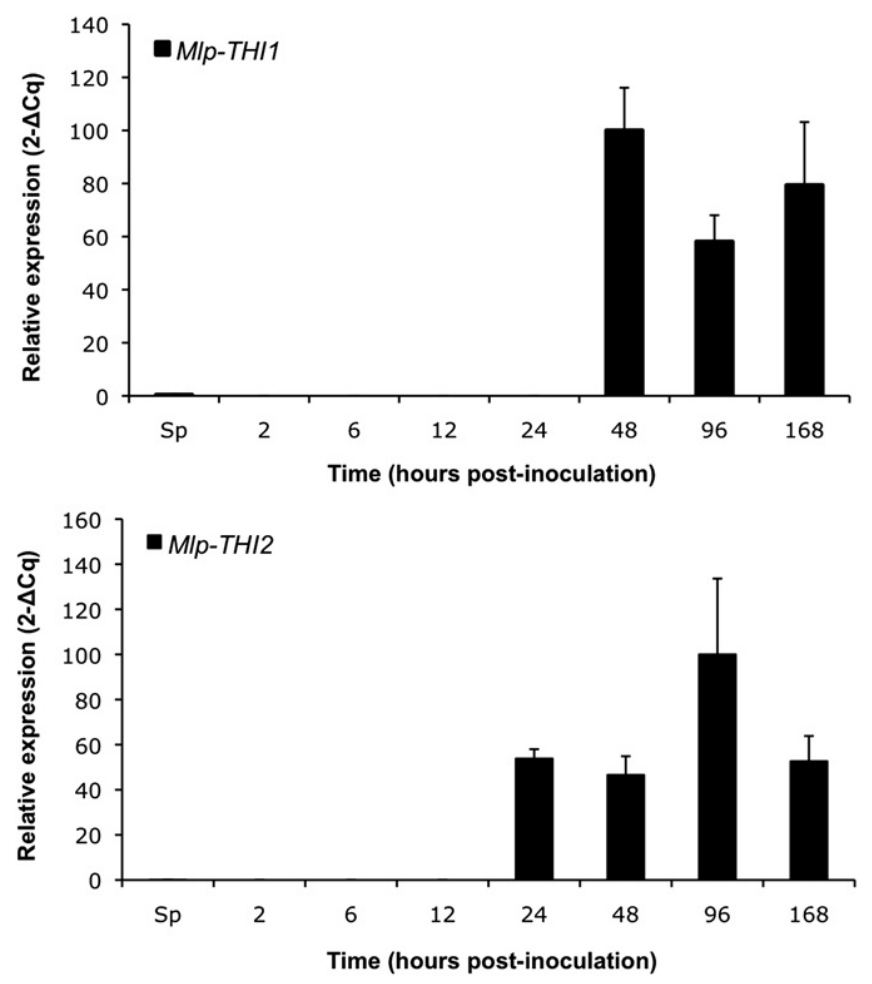

Fig. 4. Expression patterns of $M$. larici-populina thiamine biosynthesis transcripts MlpTHI1 and Mlp-THI2. Total RNA of ungerminated urediniospores and inoculated P. trichocarpa $\times$ P. deltoides 'Beaupré' leaves with M. larici-populina strain 98AG31 at 2, 6, 12 , $24,48,96$ and $168 \mathrm{~h}$ post-inoculation were isolated and aliquots of $1 \mu \mathrm{g}$ were used for first-strand cDNA synthesis. PCR was performed using $2 \mu \mathrm{l}$ of one-tenth diluted firststrand cDNA. A control with no RT in the first-strand cDNA synthesis reaction mix was included to control the lack of genomic DNA. Both Mlp-aTUB and Mlp-ELF1a transcripts were considered as reference transcripts for the calculation of Mlp-THI1 and Mlp-THI2 regulation levels $\left(2^{-\triangle \mathrm{Cq}}\right)$. For each transcript, expression regulation levels are presented as percentages of the highest regulation level measured (100\%).

Expression was not or barely detectable at early stages of 'Beaupré' leaves infection or in ungerminated urediniospores. Both transcripts showed at least a 200 -fold induction in infected leaves compared to ungerminated urediniospores suggesting their important role during the biotrophic growth phase.

\section{Discussion}

Expression profiling is an approach of choice to have a global view and a better understanding of the biological processes that control plant-pathogen interactions. Attempts to study in planta development of the barley powdery mildew fungus Blumeria graminis f. sp. hordei had been made possible through the use of transcriptome profiling [30]. Similar attempts had been also conducted in hemi-biotroph and biotroph fungal pathogens including Magnaporthe oryzae [31,32], Ustilago maydis [33] and U. fabae [34] although only few studies addressed gene expression in planta.

Most of our knowledge on expressed genes in rust fungi mostly derived from the sequencing of expressed sequence tags (ESTs) from infected leaves or isolated haustoria $[5,9,10]$. In the bean rust $U$. fabae, such approaches led to the identification of in planta induced genes (PIGs) expressed after the host plant invasion [9,34]. Transcript profiling were analysed in isolated haustoria, in infected leaves at late time-points of interaction, and in fungal structures grown in vitro in a synthetic culture system which permits to produce ex planta early infection structures similar to those produced in the plant by the rust fungus. This useful system allows 
to harvest synchronized structures such as germtubes, substomatal vesicles or infection hyphae [9]. Northern blot analyses of leaf infection by $U$. fabae helped in identifying transcripts highly or specifically expressed in the haustorial structure such as the secreted rust transferred protein 1 [17], the hexose transporter HXT1 [15] or genes involved in thiamine biosynthesis such as THI1 and THI2 [9,16]. Specific $U$. fabae gene expression was further validated in planta after haustorium formation using cDNA-array [34], unfortunately, very little is known about in planta expression of rust genes during the early stages of the plant-fungus interaction.

The qPCR technique is very sensitive and had been successfully applied to pathogen detection in field samples for various pathosystems [35,36,37]. Particularly, this technique has allowed the detection and quantification of rust fungi belonging to Melampsora spp. in poplar leaves [7,19]. The RT-qPCR technique is now commonly used in molecular studies replacing Northern blotting as a routine tool to quantify transcripts. This approach should be an excellent mean to assess gene expression in biotroph pathogens infecting their hosts. To date, only few studies reported the application of real time RT-PCR to study the relative quantification of plant pathogen gene expression in planta $[38,39,40,41]$. However, there are serious pitfalls to avoid when conducting such quantification, and it is now required to comply with simple but necessary guidelines prior using the qPCR technique for gene expression [22].

As non-cultivable organisms, biotrophic pathogens such as rust fungi require to set compatible systems with their host plant. Thus, a major concern to perform gene expression study by RT-qPCR in planta is the increase of fungal biomass during the time-course of interaction with the host. Considering this limitation, identification of genes showing a constant expression related to fungal growth is a crucial point in order to have a common reference to derive expression profiles and set comparison between genes at different time-points. To validate the use of RT-qPCR for in planta gene expression of the poplar-rust $M$. larici-populina, five candidate reference genes typically used in plant pathogen expression studies $[23,42]$ were selected and primers were defined to perform their amplification. Time-course infections have been established between $M$. larici-populina strain 98AG31 and P. trichocarpa $x$ $P$. deltoides 'Beaupré' (compatible interaction) and 'Hoogvorst' (incompatible interaction) leaves. Fungal growth was monitored in planta by qPCR using quantification of the ITS of fungal nuclear rDNA [19]. Fungal ITS amplification by qPCR during time-course infection of $P$. trichocarpa $\times P$. deltoides 'Beaupré' leaves was considered as an in planta growth curve reference for the rust fungus (Fig. 1). The assessment of the fungal growth during the compatible poplar-rust interaction is consistent with our knowledge of the progression of rust infection structures in poplar leaves as described using histology and microscopy approaches $[7,41,43,44]$. Fungal growth was limited to a basal level during the time-course incompatible interaction, which is consistent with the early and strong defense response mounted by poplar to constrain rust progression in the mesophyll [3,7]. RT Semi-qPCR profiles of rust genes during the incompatible interaction indicated lower levels of expression compared to the compatible interaction. However, as the plant express a strong defense reaction during this type of interaction (i.e. hypersensitive response, secreted pathogenesis-related proteins and proteases) [3,7], we considered that potential degradation of fungal nucleic acids might interfere with proper quantification of fungal material. Thus, we focused our analysis to the compatible interaction. The Mlp-aTUB and MlpELF1a transcripts encoding respectively an alpha-tubulin and an elongation factor-1-alpha of M. larici-populina, presented RT-qPCR Cq profiles consistent with ITS qPCR amplification curve, i.e. fungal increase during poplar leaf colonization (Fig. 3), during the compatible interaction. GeNorm is an application designed to identify the most stable genes within a selection of candidate reference genes across biological samples [27]. Both Mlp-aTUB and Mlp-ELF1a were considered by GeNorm as more stable than MlpACT and Mlp-HISTH4. Mlp-GAPDH was also tested in our experimental set-up but not detected. Finally, we considered that Mlp-aTUB and Mlp-ELF1a represent appropriate and reliable candidate reference genes to perform in planta rust transcript profiling by RT-qPCR during compatible poplar-rust interaction.

Both Mlp-aTUB and Mlp-ELF1a transcripts were used to normalize the in planta expression profiles of the thiamine biosynthesis genes THI1 and THI2 for which a specific expression was previously described in $U$. fabae haustoria [9,16]. In rust infected bean leaves, similar expression patterns were observed for $U f-T H I 1$ and $U f-T H I 2$, with no transcript detection in urediniospores and in vitro-differentiated infection structures up to $18 \mathrm{~h}$ after germination. A few transcripts were detected in $24 \mathrm{~h}$-old in vitro infection structures whereas a high mRNA accumulation was described in haustoria and rust infected leaves at 5 dpi [16]. In poplar leaves infected by $M$. larici-populina, RT-qPCR assays showed THI transcript profiles similar to those decribed for U. fabae THI genes. In the time-course infection of 'Beaupré' leaves, transcripts were barely detected in ungerminated urediniospores or at early stages of infection (i.e., 2, 6 and $12 \mathrm{hpi}$ ). Mlp-THI2 transcripts were detected after 24 hpi and Mlp-THI1 after 48 hpi (Fig. 4). In M. laricipopulina-infected poplar leaves, first haustoria have been reported at $17 \mathrm{hpi}$ and their number consistently increase at later stages until uredinia formation [43]. The results described in the present study suggest that thiamine biosynthesis likely occurs in M. larici-populina after haustorium formation. Theses results are in frame with the hypothesis of Sohn et al. [16] that haustorium is an essential structure of the biotrophic rust mycelium not only for nutrient uptake from the plant host cell but also for metabolites biosynthesis such as thiamine. This cofactor, required for the activity of several enzymes of the central carbon metabolism is strongly accumulated in $U$. fabae only during parasitic growth, suggesting that thiamine is growth limiting and not available from the host plant [16]. We can postulate that thiamine biosynthesis also plays an important role for M. larici-populina and more generally that it has a key role in rust fungi biology during host infection.

Here we demonstrated that the high sensitivity of real time PCR can help in determining pathogen gene expression in planta, even at early stages of infection when the pathogen biomass is very limited in the host. Such approach is crucial to monitor in planta transcript profiles of biotrophic fungi. Rust genomic data recently made available to the community with the sequencing of two Pucciniales genomes ( $M$. larici-populina at the Joint Genome Institute; Puccinia graminis f. sp. tritici at the Broad Institute) are valuable resources to design specific primers in order to address expression of rust transcripts during compatible interaction with their respective hosts and to get a better understanding of rust biology.

\section{Ackowledgements}

This work was supported by the Région Lorraine and the Institut National de la Recherche Agronomique (Doctoral Scholarship to Stéphane Hacquard and Junior Scientist Research Grants to Sébastien Duplessis). The authors would like to thank Patrice Vion and Bénédicte Fabre for taking care of the poplar nursery and cuttings at INRA Nancy.

\section{Appendix. Supplementary material}

Supplementary material associated with this paper can be found, in the online version, at doi:10.1016/j.pmpp.2010.10.003. 


\section{References}

[1] Pinon J, Frey P. Interactions between poplar clones and Melampsora populations and their implications for breeding for durable resistance. In: Pei MH, McCracken AR, editors. Rust diseases of willow and poplar. Wallingford, UK: CAB International; 2005. p. 139-54.

[2] Barrès B, Halkett F, Dutech C, Andrieux A, Pinon J, Frey P. Genetic structure of the poplar rust fungus Melampsora larici-populina: evidence for isolation by distance in Europe and recent founder effects overseas. Infect Genet Evo 2008;8:577-87.

[3] Duplessis S, Major I, Martin F, Séguin A. Poplar and pathogen interactions: insights from Populus genome-wide analyses of resistance and defense gene families and gene expression profiling. Crit Rev Plant Sci 2009;28 309-34.

[4] Tuskan GA, Difazio S, Jansson S, Bohlmann J, Grigoriev I, Hellsten U, et al. The genome of black cottonwood, Populus trichocarpa (Torr. and Gray). Science 2006;313:1596-604.

[5] Feau N, Bergeron M-J, Joly D, Roussel F, Hamelin R. Detection and validation of EST-derived SNPs for poplar leaf rust Melampsora medusae f. sp. deltoidae. Mo Ecol Notes 2007:7:1222-8.

[6] Miranda M, Ralph SG, Mellway R, White R, Heath MC, Bohlmann J, et al. The transcriptional response of hybrid poplar (Populus trichocarpa $x$ P. deltoides) to infection by Melampsora medusae leaf rust involves induction of flavonoid pathway genes leading to the accumulation of proanthocyanidins. Mol PlantMicrobe Interac 2007;20:816-31.

[7] Rinaldi C, Kohler A, Frey P, Duchaussoy F, Ningre N, Couloux A, et al. Transcript profiling of poplar leaves upon infection with compatible and incompatible strains of the foliar rust Melampsora larici-populina. Plant Physiol 2007;44: 347-66.

[8] Azaiez A, Boyle B, Levée V, Séguin A. Transcriptome profiling in hybrid poplar following interactions with Melampsora rust fungi. Mol Plant-Microbe Interac 2009;22:190-200.

[9] Hahn M, Mendgen K. Characterization of in planta-induced rust genes isolated from a haustorium-specific cDNA library. Mol Plant-Microbe Interac 1997; 10:427-37.

[10] Catanzariti AM, Dodds PN, Lawrence GJ, Ayliffe MA, Ellis JG. Haustorially expressed secreted proteins from flax rust are highly enriched for avirulence elicitors. Plant Cell 2006;18:243-56.

[11] Puthoff DP, Neelam A, Ehrenfried ML, Scheffler BE, Ballard L, Song Q, et al. Analysis of expressed sequence tags from Uromyces appendiculatus hyphae and haustoria and their comparison to sequences from other rust fungi. Phytopathology 2008;98:1126-35.

[12] Deising H, Jungblut PR, Mendgen K. Differentiation-related proteins of the broad bean rust fungus Uromyces viciae-fabae, as revealed by high resolution two-dimensional polyacrylamide gel electrophoresis. Arch Microbiol 1991; 155:191-8.

[13] Wirsel SGR, Voegele RT, Mendgen KW. Differential regulation of gene expression in the obligate biotrophic interaction of Uromyces fabae with its host Vicia faba. Mol Plant-Microbe Interact 2001;14:1319-26.

[14] Struck C, Mueller E, Martin H, Lohaus G. The Uromyces fabae UfAAT3 gene encodes a general amino acid permease that prefers uptake of in planta scarce amino acid. Mol Plant Pathol 2004;5:183-9.

[15] Voegele RT, Struck C, Hahn M, Mendgen K. The role of haustoria in sugar supply during infection of broad bean by the rust fungus Uromyces fabae. Proc Natl Acad Sci USA 2001;98:8133-8.

[16] Sohn J, Voegele RT, Mendgen K, Hahn M. High level activation of vitamin B1 biosynthesis genes in haustoria of the rust fungus Uromyces fabae. Mol PlantMicrobe Interac 2000;13:629-36.

[17] Kemen E, Kemen AC, Rafiqi M, Hempel U, Mendgen K, Hahn M, et al. Identification of a protein from rust fungi transferred from haustoria into infected plant cells. Mol Plant-Microbe Interac 2005;18:1130-9.

[18] Gachon C, Saindrenan P. Real-time PCR monitoring of fungal development in Arabidopsis thaliana infected by Alternaria brassicicola and Botrytis cinerea. Plant Physiol Biochem 2004;42:367-71.

[19] Boyle B, Hamelin RC, Seguin A. In vivo monitoring of obligate biotrophic pathogen growth by kinetic PCR. Appl Environ Microb 2005;71:1546-52.

[20] Demontis MA, Cacciola SO, Orru M, Balmas V, Chessa V, Maserti BE, et al. Development of real-time PCR systems based on SYBR ${ }^{\circledR}$ Green I and TaqMan ${ }^{\circledR}$ technologies for specific quantitative detection of Phoma tracheiphila in infected Citrus. Eur J Plant Pathol 2008;120:339-51.
[21] Stephens AE, Gardiner DM, White RG, Munn AL, Manners JM. Phases of infection and gene expression of Fusarium graminearum during crown rot disease of wheat. Mol Plant-Microbe Interac 2008;21:1571-81.

[22] Bustin SA, Benes V, Garson JA, Hellemans J, Huggett J, Kubista M, et al. The MIQE guidelines: minimum information for publication of quantitative realtime PCR Experiments. Clinic Chem 2009;55:611-22.

[23] Fang W, Bidochka MJ. Expression of genes involved in germination, conidiogenesis and pathogenesis in Metarhizium anisopliae using quantitative realtime RT-PCR. Mycol Res 2006;110:1165-71.

[24] Bohle K, Jungebloud A, Göcke Y, Dalpiaz A, Cordes C, Horn H, et al. Selection of reference genes for normalisation of specific gene quantification data of Aspergillus niger. J Biotechnol 2007;132:353-8.

[25] Sambrook J, Russell DW. Molecular cloning: a laboratory manual. Ed 3, vols 1-3. Cold Spring Harbor, NY: Cold Spring Harbor Laboratory Press; 2001.

[26] Livak KJ, Schmittgen TD. Analysis of relative gene expression data using realtime quantitative PCR and the 2-DDC $(\mathrm{t})$ method. Methods 2001;25:402-8.

[27] Vandesompele J, De Preter K, Pattyn F, Poppe B, Van Roy N, De Paepe A, et al. Accurate normalization of real-time quantitative RT-PCR data by geometric averaging of multiple internal control genes. Genome Biol 2002;3:R0034.

[28] Nolan T, Hands RE, Ogunkolade W, Bustin SA. SPUD: a quantitative PCR assay for the detection of inhibitors in nucleic acid preparations. Anal Biochem 2006;351:308-10.

[29] Pfaffl MW. A new mathematical model for relative quantification in real-time RT-PCR. Nucl Acids Res 2001;29:e45.

[30] Both M, Eckert SE, Csukai M, Müller E, Dimopoulos G, Spanu PD. Transcript profiles of Blumeria graminis development during infection reveal a cluster of genes that are potential virulence determinants. Mol Plant-Microbe Interac 2005; 18:125-33.

[31] Dean RA, Talbot NJ, Ebbole DJ, Farman ML, Mitchell TK, Orbach MJ, et al. The genome sequence of the rice blast fungus Magnaporthe grisea. Nature 2005;434:980-6.

[32] Oh Y, Donofrio N, Pan H, Coughlan S, Brown DE, Meng S, et al. Transcriptome analysis reveals new insight into appressorium formation and function in the rice blast fungus Magnaporthe oryzae. Genome Biol 2008;9:R85.

[33] Kämper J, Kahmann R, Bölker M, Ma LJ, Brefort T, Saville BJ, et al. Insights from the genome of the biotrophic fungal plant pathogen Ustilago maydis. Nature 2006;444:97-101.

[34] Jakupović M, Heintz M, Reichmann P, Mendgen K, Hahn M. Microarray analysis of expressed sequence tags from haustoria of the rust fungus Uromyces fabae. Fungal Genet Biol 2006;43:8-19.

[35] Schena L Nigro F, Ippolito A, Gallitelli D. Real-time quantitative PCR: a new technology to detect and study phytopathogenic and antagonistic fungi. Eur J Plant Pathol 2004;110:893-908.

[36] Hayden K, Ivors K, Wilkinson C, Garbelotto M. TaqMan Chemistry for Phytophthora ramorum detection and quantification, with a comparison of diagnostic methods. Phytopathology 2006;96:846-54.

[37] Lievens B, Brouwer M, Vanachter ACRC, Cammue BPA, Thomma BPHJ. Realtime PCR for detection and quantification of fungal and oomycete tomato pathogens in plant and soil samples. Plant Sci 2006;171:155-65.

[38] Avrova AO, Venter E, Birch PR, Whisson SC. Profiling and quantifying differential gene transcription in Phytophthora infestans prior to and during the early stages of potato infection. Fungal Genet Biol 2003;40:4-14.

[39] Desmond OJ, Manners JM, Schenk PM, Maclean DJ, Kazan K. Gene expression analysis of the wheat response to infection by Fusarium pseudograminearum. Physiol Mol Plant Pathol 2008;70:40-7.

[40] Zhang Y, Qu Z, Zheng W, Liu B, Wang X, Xue X, et al. Stage-specific gene expression during urediniospore germination in Puccinia striiformis f. sp tritici. BMC Genomics 2008;9:203.

[41] Hacquard S, Delaruelle C, Legué V, Tisserant E, Kohler A, Frey P, et al. Laser capture microdissection of uredinia formed by Melampsora larici-populina revealed a transcriptional switch between biotrophy and sporulation. Mol Plant-Microbe Interact 2010;23:1275-86.

[42] Yan HZ, Liou RF. Selection of internal control genes for real-time quantitative RT-PCR assays in the oomycete plant pathogen Phytophthora parasitica. Fungal Genet Biol 2006;43:430-8.

[43] Laurans F, Pilate G. Histological aspects of a hypersensitive response in Poplar to Melampsora larici-populina. Phytopathology 1999;89:233-8.

[44] Boyle B, Levée V, Hamel LP, Nicole MC, Séguin A. Molecular and histochemical characterisation of two distinct poplar Melampsora leaf rust pathosystems. Plant Biol 2010;12:364-76. 